\title{
A Indústria Vinícola no Vale do São Francisco e as Estratégias de Inserção no Mercado Nacional: Uma Revisão Bibliográfica
}

\author{
Pedro Vieira Souza Santos \\ Universidade Federal do Vale do São Francisco, Univasf, Brasil \\ pedrovieirass@hotmail.com
}

\section{RESUMO}

O termo estratégia tem se tornado um assunto muito utilizado pelas organizações, sendo ela realizada de diversas maneiras pelos gestores da organização que define e implanta as estratégias nas empresas. Assim observado, no ambiente empresarial de hoje, as empresas que conseguem atuar com qualidade como forma de satisfazer o cliente terão maior competitividade no mercado em que atuam, garantindo assim sua sobrevivência e permanência e talvez até sua expansão no mercado. Logo, o objetivo central deste artigo foi estudar, a partir da revisão da literatura, as estratégias de inserção no mercado brasileiro e as barreiras enfrentadas pelas vinícolas do Vale do São Francisco pernambucano. Tal investigação se deu com base nos conceitos de Cadeias Agroindustriais e Coordenação de Cadeias Produtivas, os quais abrangem as relações entre fornecedores e clientes e as estratégias competitivas. Pôde-se concluir que, apesar de ser um setor consolidado no mercado local, a indústria vinícola ainda enfrenta diversas barreiras que comprometem seu desenvolvimento em nível nacional.

PALAVRAS-CHAVE: Indústria vinícola. Estratégia. Revisão bibliográfica. 


\title{
The Wine Industry in the Valley of São Francisco and the Strategies of Insertion in the National Market: A Bibliographic Review
}

\begin{abstract}
The term strategy has become a subject widely used by organizations, and the same is done in several ways by the managers of the organization that defines and implements strategies in companies. Thus, in today's business environment, companies that manage to act with quality as a way to satisfy the customer will have a greater competitiveness in the market in which they operate, thus ensuring their survival and permanence and perhaps even expansion in the market. Therefore, the main objective of this article was to study, from the literature review, the strategies of insertion in the Brazilian market and the barriers faced by the wineries of the São Francisco Valley of Pernambuco. This research was based on the concepts of Agroindustrial Chains and Coordination of Productive Chains, which cover the relations between suppliers and clients and the competitive strategies. It could be concluded that despite being a consolidated sector in the local market, the wine industry still faces several barriers that jeopardize its development at the national level.
\end{abstract}

KEY-WORDS: Wine industry. Strategy. Literature review. 


\section{INTRODUÇÃO}

No ambiente empresarial de hoje, as empresas que conseguem atuar com qualidade como forma de satisfazer o cliente terão maior competitividade no mercado em que atuam, garantindo assim sua sobrevivência e permanência e talvez até sua expansão no mercado.

Assim, tão importante quanto saber qual a melhor decisão a ser tomada é saber o que não fazer, pois o mercado está em constante mudança e para adequar-se a esse ambiente é importante que a empresa tenha objetivos definidos e que todos que compõem a organização os conheçam, para que assim possam trabalhar em equipe na construção e no aprimoramento de atividades a fim de alcançar o sucesso empresarial (Bucheroni, 2015).

A competitividade global de uma empresa depende profundamente de sua eficiência na comercialização de seus insumos e produtos. Quanto mais adequado for o esquema de coordenação entre os componentes do sistema, intermediados por mecanismos de comercialização, menores serão os custos de cada um deles, mais rápida a adaptação às modificações de ambiente e menos custosos serão os conflitos inerentes às relações entre cliente e fornecedor (Azevedo, 2007).

Logo, a competitividade organizacional pode ser entendida como o núcleo do sucesso ou do fracasso das organizações (Campos, 2004). A competição é responsável pela adaptação da empresa ao seu ambiente de atuação, fruto das estratégias competitivas adequadas que ela utiliza.

Nesse aspecto, a satisfação dos clientes torna-se um fator determinante na sobrevivência e conquista de espaço no mercado, sendo possível afirmar que a satisfação resulta da compreensão e tradução das necessidades dos clientes em características de produtos. Essa compreensão do cliente impacta nas vendas, na participação no mercado e, consequentemente, nos resultados financeiros obtidos (Balbim \& Bornia, 2011).

Logo, a vantagem competitiva pressupõe o ato de chegar primeiro ao cliente, de estar à frente da concorrência ofertando um diferencial e, 
consequentemente, conquistando maior parcela do mercado, por isso se torna importante analisar o ambiente e procurar entender o comportamento dos concorrentes e clientes. "A estratégia competitiva significa escolher um diferente arranjo de atividades para entregar um composto de valor único, marcando uma posição estratégica competitiva." (Porter, 1996, citado por Chiavenato, 2007, p. 117)

Associado a isso, o termo estratégia tem se tornado um assunto muito utilizado pelas organizações, sendo ela realizada de diversas maneiras pelos gestores da organização que define e implanta as estratégias nas empresas (Fernandes et al., 2013). "Ao implementar uma estratégia, o acompanhamento de todas as suas fases, pelos diversos executivos da empresa, é de fundamental importância para os resultados que se pretende alcançar." (Oliveira, Perez \& Silva, 2005, p. 50)

Ainda de acordo com Oliveira, Perez e Silva (2005), estratégia é uma atividade que deve estar envolvida no processo decisório das organizações, pois possibilita um amplo conhecimento dos negócios e a verificação das tendências do mercado. O objetivo da estratégia empresarial é avaliar as forças e as fraquezas, saber os limites da organização, saber atacar os concorrentes no momento certo, recuar quando for necessário, buscar condições favoráveis à empresa e realizar parcerias com as demais organizações (Dias, 2003).

Segundo Oliveira et al. (2005, p. 32), "objetivo estratégico representa tudo o que é vital para uma organização ou unidades de negócio para manter sua capacidade competitiva e incrementar suas vantagens em relação aos concorrentes atuais e futuros".

Para Kotler e Keller (2006), a estratégia é um plano de como chegar lá. Cada negócio deve estabelecer a própria estratégia para atingir suas metas. Ferrell e Hartline (2005) citam que a estratégia de marketing basicamente se define em como a empresa irá satisfazer as necessidades e os desejos de seus clientes.

Portanto, nesse contexto, com alta competitividade e clientes mais exigentes, as empresas passam a analisar melhor os ambientes competitivos na escolha de suas estratégias, a fim de se manter no mercado e consequentemente obter melhores resultados frente à 
concorrência. Uma das estratégias utilizadas pelas empresas é a estratégia genérica de Porter (Guetta et al., 2013).

Então, a partir do cenário exposto, o objetivo central deste artigo é estudar, a partir da revisão da literatura, as estratégias de inserção no mercado brasileiro e as barreiras enfrentadas pelas vinícolas do Vale do São Francisco pernambucano. Tal investigação se dará com base nos conceitos de Cadeias Agroindustriais e Coordenação de Cadeias Produtivas, os quais abrangem as relações entre fornecedores e clientes e as estratégias competitivas.

\section{REFERENCIAL TEÓRICO}

\subsection{BARREIRAS DE ENTRADA}

Segundo Melo et al. (2014), a expressão "barreiras de entrada" teve sua primeira publicação na obra de Bain (1956), que as considera correguladoras de conduta e desempenho das atividades empresariais. Ou seja, as barreiras de entrada estão relacionadas aos novos entrantes, na medida em que facilitam ou dificultam que novas empresas façam parte da concorrência.

Na visão de Carlton e Perloff (1994), quando se fala em barreira à entrada, diz-se que são condições que impedem instantaneamente um empresário de desenvolver a criação de uma nova empresa em um mercado. Carlton (2004) afirma em seu estudo que o número de empresas em determinado mercado é definido pela sua capacidade de ganhar lucro, o que depende de muitos fatores, não apenas estruturais.

Porter (1999) classifica barreiras de entrada em três tipos: (1) barreiras tecnológicas (os investimentos em tecnologia capazes de gerar competitividade frente aos rivais já consolidados no mercado) aqui, o volume dos recursos a serem investidos em aquisição ou aprimoramento tecnológico depende de quão dependente de tecnologia é a atividade; (2) barreiras regulatórias (legislação vigente); (3) barreiras "informacionais".

Nesse sentido, em seu modelo de análise da concorrência, Porter (1999) identifica como principais barreiras de entrada as economias de 
escala, a diferenciação de produto, as necessidades de capital, os custos de mudança de fornecedor, o acesso aos canais de distribuição, as políticas governamentais e as desvantagens de custo independentes da escala, descritas a seguir.

A economia de escala está associada à detenção da entrada, conduzindo a empresa entrante a ingressar em larga escala e também a assumir o risco de uma forte reação das empresas existentes, ou a ingressar em pequena escala e enfrentar uma desvantagem de custo.

A diferenciação do produto refere-se à marca identificada e ao nível de lealdade desenvolvidos pelas empresas estabelecidas diante dos clientes.

A necessidade de capital exige investimento de recursos financeiros para atividades arriscadas e irrecuperáveis como a publicidade inicial ou para pesquisa e desenvolvimento (P\&D).

Os custos de mudança são uma barreira de entrada, ou seja, custos com que se defronta o comprador quando muda de um fornecedor de produto para outro.

O acesso aos canais de distribuição pode ser criado pela necessidade de a nova entrante assegurar a distribuição do produto.

A política governamental diz respeito à possibilidade de o governo limitar ou até mesmo impedir a entrada em indústria com controles como licenças de funcionamento e limites de acesso às matérias-primas.

Para a desvantagem de custo independente de escala, Porter enuncia ainda alguns fatores que apresentam vantagens plenas de custos para as empresas estabelecidas em uma indústria, impossíveis de ser igualadas pelos entrantes potenciais, independentemente de economia de escala. Tais fatores são os seguintes: (a) tecnologia patenteada do produto; (b) acesso favorável às matérias-primas (as empresas estabelecidas têm o controle das fontes de matérias-primas mais favoráveis, ou têm sob controle preços muito mais baixos do que o normal); c) localizações favoráveis; (d) subsídios oficiais (subsídios preferenciais do governo); e (e) curva de aprendizagem ou experiência (os 
custos declinam à medida que uma empresa acumula experiência na fabricação do produto).

Porém, segundo Porter (1999), os efeitos da experiência refletem na redução dos custos - no marketing, na produção, na distribuição e, principalmente, nas ações que envolvem alto grau de participação de mão de obra em operações e tarefas complicadas.

Ainda segundo o autor, se as barreiras de entrada apresentam complexidade, os novos entrantes devem esperar certo grau de reação, dessa forma a ameaça de entrada pode ser considerada pequena.

\subsection{AS ESTRATÉGIAS COMPETITIVAS BÁSICAS}

A estratégia é planejada para identificar qual a posição em que a organização se encontra no mercado e aonde ela pretende chegar, portanto, segundo Bateman e Snell (1998, p. 126):

A administração estratégica integra planejamento estratégico e a administração em um único processo. O planejamento estratégico torna-se uma atividade contínua em que todos os administradores são encorajados a pensar estrategicamente e a focalizar tanto questões externas a longo prazo quanto questões táticas e operacionais a curto prazo.

De acordo com Bhalla et al. (2009), a gestão estratégica surgiu como uma disciplina híbrida, influenciada tanto pela sociologia quanto pela economia. Assim, Barney (2001) considera que a estratégia é uma teoria empresarial que trata sobre como competir com sucesso. Ainda para o autor, o desempenho é um fator influenciado pela estratégia, pois, na sua percepção, competir com sucesso significa ter um desempenho satisfatório.

Nesse contexto, as estratégias de marketing amplas, também conhecidas como estratégias competitivas básicas, colaboram com 0 posicionamento da empresa frente ao mercado. Logo, Porter (1999) sugere três abordagens genéricas, descritas a seguir.

Pela liderança pelo custo total, adota-se uma posição de custos mais baixos do que os da concorrência, mantendo a qualidade. Contudo, os preços altamente competitivos são resultado do empenho da empresa em 
reduzir os custos da produção e distribuição, deixando-os abaixo do custo dos seus adversários. Assim, a empresa consegue ter maior retorno financeiro e também ampliar sua participação no mercado.

Pela diferenciação, a empresa busca ser única no mercado, oferecendo algo único ao segmento. Consiste em criar produtos e serviços considerados únicos pelas pessoas. A reputação da empresa, nesses casos, está diretamente relacionada à qualidade, à liderança em tecnologia e à tradição no mercado.

Pelo foco, uma empresa tem como objetivo atingir um público-alvo determinado, ou seja, segmentos e nichos restritos ainda não atendidos. 0 foco também pode ser usado para mostrar segmentos do público nos quais os concorrentes são fracos. Nesse caso, a empresa alcança a diferenciação por conhecer bem o setor. Assim, tem-se uma combinação das duas estratégias anteriores focadas em um público específico.

Nesse contexto, de acordo com Oliveira (1996, citado por Vitorino, Peresin \& Sacomano, 2011), a finalidade da estratégia é apresentar caminhos a serem seguidos para que seja possível alcançar os objetivos e enfrentar desafios estabelecidos pelas organizações.

O autor ainda subdivide estratégia em quatro: estratégia de sobrevivência, estratégia de manutenção, estratégia de crescimento e estratégia de desenvolvimento.

A estratégia de sobrevivência somente deve ser adotada quando não houver alternativa.

A adoção da estratégia de manutenção é aconselhada em casos em que a empresa está enfrentando ou espera encontrar dificuldades e, diante dessa situação, prefere tomar uma atitude defensiva frente às ameaças.

Pela estratégia de crescimento, apesar de haver muitos pontos fracos na empresa, há, ao mesmo tempo, chances de transformá-los em oportunidades.

Por outro lado, a estratégia de desenvolvimento é caracterizada pela predominância de pontos fortes e de oportunidades e, neste caso, nada melhor do que desenvolver a empresa. 
Com base no que foi exposto, pode-se dizer que a estratégia é um conjunto de regras de tomada de decisão em condições de desconhecimento parcial. Contudo, as decisões estratégicas dizem respeito à relação entre a empresa e o seu ecossistema, levando-se em consideração meios, produtos, mercado, vetor, crescimento, vantagem competitiva e sinergia (Vitorino et al., 2011).

Em suma, pode-se dizer que o termo estratégia corresponde a um fator mediador entre a organização e seus ambientes, com foco nas decisões e ações que ocorrem naturalmente. Salienta-se que a formação de estratégias não se limita a processos, mas pode ocorrer como um padrão de ações formalizadas (Mintzberg, Ahlstrand \& Lampel, 1998).

\subsection{ESTRATÉGIAS DE POSICIONAMENTO}

"Posicionamento é o ato de desenvolver a oferta e a imagem da empresa para ocupar um lugar destacado na mente dos clientes-alvo." (Kotler \& Keller, 2012, p. 321)

Em outras palavras, entende-se posicionamento como o ato de posicionar, por meio de estratégias e ações de marketing, um produto, ou uma marca, para que ele ocupe um lugar de destaque na preferência do cliente.

Kotler e Keller (2012) afirmam que é muito mais proveitoso para a empresa focar suas atividades em nichos específicos e adotar posicionamentos de acordo com o mercado-alvo escolhido. Para os autores, o posicionamento é feito com base em duas variáveis: o tipo de consumidor que se deseja atender, os tipos de consumidores são explicitados na segmentação do mercado; e a proposta de valor que a empresa deseja oferecer.

Assim, o resultado final do posicionamento é a criação bemsucedida de uma proposta de valor localizada no mercado, isto é, uma razão convincente para que o mercado-alvo compre o produto oferecido (Kotler \& Keller, 2012).

Além disso, a identificação de segmentos-alvo, a avaliação desses segmentos segundo sua atratividade e a identificação das capacidades 
competitivas da empresa conduzem-na a uma oferta diferenciada, ou seja, permitem que a empresa ofereça para o mercado-alvo um produto ou marca que se distingue dos demais concorrentes em termos de características e/ou custos (Gouvêa \& Niño, 2010).

Nesse sentido, as estratégias de posicionamento devem ser baseadas na diferenciação das ofertas e inseridas em um segmento específico de mercado, para tanto a construção de uma identidade de posicionamento eficaz deve ser baseada na segmentação e no diferencial, que satisfaçam alguns critérios citados por Kotler (2000).

O autor afirma que todos os produtos podem ser diferenciados até certo ponto. Mas nem todas as diferenças são significativas ou valem a pena. É necessário estabelecer uma diferença até o ponto em que ela satisfaça os seguintes critérios (Kotler, 2000):

- importância: a diferença oferece um benefício de alto valor a um número suficiente de compradores;

- destaque: a diferença é oferecida de maneira destacada;

- $\quad$ superioridade: a diferença é superior a outras maneiras de obter benefícios;

- exclusividade: a diferença não pode ser facilmente copiada pelos concorrentes;

- $\quad$ acessibilidade: o comprador deve poder pagar pela diferença;

- Iucratividade: a empresa deve considerar a diferença lucrativa.

Para Porter (2004), uma análise competitiva permite observar os relacionamentos e a dinâmica em um ramo de negócio, possibilitando à empresa tomar decisões estratégicas a respeito de qual posição é mais defensável e mais atraente economicamente. Ademais, Mintzberg et al. (2000) sustentam que a estratégia como posição significa a localização de determinados produtos em determinados mercados.

Nesse contexto, Kotler e Keller (2012) apresentam seis alternativas ou "estratégias de posicionamento do produto" em relação ao segmento de mercado, descritas a seguir.

- Posicionamento por atributo: ocorre quando uma empresa estabelece seu posicionamento com base na performance do produto em 
alguns atributos específicos, tangíveis ou abstratos. Aspectos que caracterizam a noção de qualidade que um consumidor percebe do produto são [...] Peso, Textura, Cor, Embalagem, Aparência geral, Durabilidade, Publicidade e Promoção [...] (Kotler \& Armstrong, 2003).

Os autores apontam que por meio das características e atributos, o consumidor toma atitudes (julgamentos, preferências) relacionadas com as várias marcas disponíveis no mercado. Assim, a empresa precisa monitorar e entender seu ambiente de marketing e os diferentes tipos de mercados em que as marcas competem.

- Posicionamento por benefícios: apresenta não apenas os resultados de desempenho do produto em certos atributos, mas também os benefícios que eles apresentam; aqui, o produto é posicionado como líder em determinado benefício.

Além disso, segundo Toledo e Hemzo (1991, citados por Gouvêa \& Niño, 2010, p. 8), uma oferta diferenciada refere-se "[...] ao estabelecimento de um pacote de benefícios ou valores expressos por produto, preço, distribuição e por todo o mix de capacidades e serviços de suporte da empresa".

Assim, os benefícios recebidos podem incluir algo que os clientes recebem ao lidar com a empresa. Eles percebem benefícios baseados também em suas experiências com a empresa e com a marca. No próprio ato da compra, o benefício pode ser constatado e influenciado. Para Kotler e Keller (2006), as promoções na loja, demonstrações, degustações e até a promoção fora da loja, como a propaganda, podem ser incluídas nos benefícios de experiência percebidos pelo consumidor.

Nesse sentido, este posicionamento tem seu foco em identificar quais segmentos desejam quais benefícios dentro de cada mercado para oferecer, então, o que cada um deles quer. Por isso, conforme Hooley, Saunders e Piercy (2005, citados por Luz, 2014), este tipo também pode exigir habilidade para o desenvolvimento de novos bens/serviços, visando assegurar que os benefícios procurados sejam realmente entregues aos clientes por meio da construção dos atributos relevantes.

- Posicionamento por uso/aplicação: apresenta o produto como mais apropriado para ser usado ou aplicado em uma situação específica, ou 
seja, empenha-se em destacar a facilidade de uso e aplicação do seu produto/serviço em relação aos concorrentes.

Logo, trata-se do posicionamento que sugere algum benefício da marca para o uso específico daquele produto. Conforme Lupetti (2012, citado por Luz, 2014), aqui não significa que a marca ou organização seja pioneira ou ofereça um produto ou serviço exclusivo: é possível que outras possam "imitar" esse posicionamento e ele seja dividido com concorrentes.

- Posicionamento por usuário: associa o produto a determinada categoria de usuário, com base em características como estilo de vida, traços de personalidade, história de vida, etc.

Trata-se aqui de qualidade do foco, e não de quantidade. Aqui se pode incluir uma subcategoria chamada de posicionamento customizado, que, conforme Hooley, Saunders e Piercy (2005), envolve a compreensão das exigências individuais dos clientes e a construção de relacionamentos um a um, ao invés de atender às necessidades do mercado em geral.

- Posicionamento por concorrente: compara, de forma implícita ou explícita, o produto ou marca com um concorrente, buscando facilitar a compreensão do posicionamento ou situar-se como uma alternativa melhor que a do concorrente, ou seja, ocorre quando uma marca ou organização posiciona-se apoiada na comparação em relação à concorrência, com base em algum diferencial competitivo do produto ou potencial desenvolvido em seu mix de marketing.

- Posicionamento por categoria de produto: ranqueia o produto como líder em determinada categoria; é mais usado quando se trata de novos produtos, pois permite enfatizar as diferenças de características entre ele e os demais existentes no mercado. Neste caso, este tipo de posicionamento implica criar uma categoria não explorada, como o próprio nome diz. Ou seja, ocorre quando uma marca ou organização cria uma nova categoria de bens ou serviços em que ela poderá ser pioneira.

Assim sendo, as organizações têm várias formas de posicionar seus produtos, oferecendo o valor aos clientes e o valor no mercado. O posicionamento vai depender dos públicos-alvo e das estratégias de cada organização. Porém, é preciso tomar cuidado para que as organizações evitem os seguintes erros ao posicionar-se: subposicionamento; 
superposicionamento; posicionamento confuso; posicionamento irrelevante e posicionamento duvidoso (Kotler, 1998).

Portanto, nota-se que há uma relação intensa entre posicionamento e estratégia: o posicionamento relaciona-se com a estratégia do ponto de vista da continuidade do processo de segmentação e pela busca de posições de mercado cujas forças concorrenciais possam ser defendidas ou tenham menor intensidade com possibilidade de buscar posições ainda não ocupadas, ou seja, onde não haja concorrência (Porter, 2004).

Desse modo, é importante pensar em como efetivar essas estratégias. Nesse sentido, o composto de marketing tem decisivo papel e importância, pois tem de estar aliado às estratégias das organizações (Lins et al., 2010).

Logo, entende-se o composto de marketing como o conjunto de ferramentas que as empresas utilizam para alcançar os objetivos de marketing no mercado-alvo. Tais ferramentas, segundo Kotler e Keller (2006), estão classificadas em quatro grupos amplos que se denominou de 4Ps do marketing: produto, preço, praça (localização) e promoção.

Os 4Ps, preconizados pelo professor Jerome McCarthy (1978), são uma forma de estudar produto, preço, praça e promoção como componentes do composto de marketing. Embora, de acordo com Popovic (2006), este conceito tenha sido criticado por ser uma definição de marketing orientada para a produção, e não para o cliente, reflete uma forma de gerenciamento do setor de marketing nas organizações. Nesse sentido, Schultz (2001) cita ainda que os mercados atuais são orientados para o cliente, ou seja, os 4Ps possuem menos relevância hoje, sendo, para o autor, necessária sua atualização.

O primeiro " $\mathrm{P}$ ", que se relaciona ao Produto, pode ser um serviço ou ideia para satisfazer as necessidades dos consumidores. Kotler e Keller (2006) afirmam que o produto pode ser definido como tudo o que pode ser oferecido a um mercado para satisfazer uma necessidade ou um desejo, ou seja, bens físicos, serviços, experiências, eventos, pessoas, lugares, propriedades, organizações, informações e ideias. 
Por outro lado, o segundo "P", a variável Preço, como salientam Kotler e Keller (2006), é o único elemento do composto de marketing que produz receita, os demais produzem custo. Os autores avaliam ainda que, por meio da determinação do preço, uma empresa pode perseguir objetivos que definem estratégias como as de sobrevivência, maximização do lucro atual, maximização da participação de mercado ou liderança de qualidade de produto. Os itens restantes que tangem o composto Preço, para os quais estão previstos descontos, concessões, condições e prazos de pagamento, são igualmente importantes, mas devem levar em consideração principalmente o momento e a circunstância da venda, baseados também em uma realidade de mercado imposta pela concorrência, com o intuito de igualar-se ou criar diferencial competitivo.

Já o terceiro "P", que se relaciona à Promoção, é tido como o marketing moderno. Trata-se muito mais do que apenas criar bons produtos e disponibilizá-los ao mercado consumidor, é indispensável neste processo a comunicação com os clientes (Kotler \& Keller, 2006). De acordo com os autores, as principais ferramentas do Composto Promoção são: propaganda, promoção de vendas, venda pessoal e relações públicas.

Por fim, o último "P" é a Praça, que se traduz em uma forma de colocar o produto na mão dos consumidores através do mercado-alvo (Corrêa, Murini, Becker \& Bolignon, 2012). Segundo Kotler e Keller (2006), o Ponto de Vendas ou Praça pode ser entendido como a combinação de agentes entre os quais o produto flui, desde o vendedor inicial (geralmente o fabricante) até o consumidor final. Uma empresa pode, dependendo da logística planejada, utilizar-se do atacadista, do distribuidor, do varejista, do correio, de loja própria, ou de qualquer outro canal para distribuir seus produtos na praça.

Nessa perspectiva, o resultado final do posicionamento é a criação bem-sucedida de uma proposição de valor focada no mercado, uma declaração simples do motivo pelo qual um dado mercado-alvo deve comprar certo produto (Kotler \& Keller, 2006).

Portanto, é de suma importância a análise do composto de marketing para o melhor entendimento das estratégias da empresa e seus processos diários. Além disso, de que forma se estabelece o 
relacionamento entre a empresa e seus consumidores internos e externos, é o que permite encontrar os pontos fracos e fortes nesse processo de interação (Corrêa et al., 2012).

\section{METODOLOGIA}

Segundo Noronha e Ferreira (2000, citados por Silva, Bagno \& Salerno, 2014), as revisões de literatura são estudos importantes quando o objetivo é identificar, conhecer e acompanhar o desenvolvimento da pesquisa em determinada área do conhecimento. Além disso, esse tipo de trabalho contribui para o desenvolvimento de novas pesquisas, uma vez que permite a identificação de lacunas do conhecimento e perspectivas futuras. Fink (2005) define a revisão de literatura como um método sistemático, explícito e reprodutível para identificar, avaliar e sintetizar o corpo existente de trabalho completo e produzido por pesquisadores, estudiosos e profissionais.

Logo, a pesquisa geradora deste artigo pode ser classificada quanto ao objetivo como exploratória e descritiva, uma vez que o levantamento das abordagens de diferentes autores acerca da temática de estratégias empresariais e competitividade inicia-se na identificação, apontamento e compreensão dos atributos dos diversos estudos ligados ao assunto e das relações entre eles. Zikmund (2003) observa que, na pesquisa exploratória, inicialmente devem ser analisados os estudos existentes na área em questão, para, em seguida, converter questões potenciais em problemas mais definidos para construir os objetivos de pesquisa.

Para o desenvolvimento da pesquisa, foram definidas três etapas. $\mathrm{Na}$ primeira, selecionaram-se as seguintes palavras-chave: "estratégia", "vinícolas", "Vale do São Francisco" e "competitividade". Posteriormente, utilizando a ferramenta de busca do portal Periódicos Capes (Coordenação de Aperfeiçoamento de Pessoal de Nível Superior), essas palavras foram introduzidas nos campos apropriados para uma busca integrada. Porém, ressalta-se que, além deste portal, realizaram-se também pesquisas em anais de eventos tradicionais e reconhecidos na área e em revistas eletrônicas. 
$\mathrm{Na}$ segunda fase, realizou-se a leitura dos artigos objetivando verificar a afinidade dessas publicações com a temática tratada. No total, foram selecionados 27 artigos, provenientes de 16 periódicos, a maioria em língua portuguesa e inglesa.

$\mathrm{Na}$ análise do conteúdo de cada artigo, buscou-se identificar os seguintes elementos: qualidade dos artigos selecionados; periódicos em que foram publicados; conceitos de inovação e estratégia e modelo teórico proposto ou adotado pelo autor para base de discussão, assim como as conclusões apontadas pelo autor. Nesta avaliação excluíram-se publicações com acesso limitado a resumo, assim como aquelas com baixa relevância das discussões.

Por fim, extraíram-se as principais informações sobre os resultados e apontamentos dos estudos publicados e consultados sobre a temática tratada e seus respectivos direcionamentos. Contudo, salienta-se que todas as fontes consultadas e citadas neste artigo foram devidamente referenciadas a fim de garantir a manutenção dos direitos autorais.

\section{RESULTADOS E DISCUSSÃO}

\subsection{A INDÚSTRIA VINÍCOLA}

Os vinhos no Brasil, a partir dos anos 1990, têm sido reconhecidos internacionalmente através de premiações nacionais e internacionais. Estes resultados indicam que as vinícolas brasileiras têm investido na busca da qualidade do produto, com o objetivo de atingir um padrão internacional e competir com os vinhos importados que chegam às prateleiras do mercado brasileiro (Sato, 2006). Quando se fala na qualidade desejada do vinho, esta depende, majoritariamente, da qualidade da uva empregada como matéria-prima, que está intimamente relacionada com as condições do solo e do clima, entre outras.

Entretanto, vale ressaltar que o mercado de vinho caracteriza-se pela grande complexidade, em virtude, entre outros motivos, da enorme diversidade dos tipos de vinho e da multiplicidade das legislações nacionais a respeito (Rosa \& Simões, 2004). Em relação ao tipo de vinho, de acordo 
com Thomé et al. (2013), no Brasil elabora-se, predominantemente, dois tipos: o vinho de mesa e o vinho fino. O primeiro tipo é feito de uvas americanas e híbridas (provenientes do cruzamento de diferentes espécies); já o vinho fino é produzido utilizando-se uvas vitis vinifera, de origem europeia.

Contudo, apesar desse fato, o Brasil possui muitas regiões produtoras de vinho em todo seu território. Dentre as principais, destacamse a região sul e o Nordeste, no Vale do São Francisco. No Sudeste, destacam-se, principalmente, os estados de São Paulo e Minas Gerais (Toledo \& Ferreira, 2016). O estado do Rio Grande do Sul concentra 90\% da produção nacional, nas regiões da Serra Gaúcha, Campanha e Serra do Sudeste, onde há predominância do cultivo de uva em pequenas propriedades rurais. O estado de Santa Catarina é outro grande produtor na região sul, mais especificamente com a produção concentrada no Vale do Rio do Peixe (Ibravin, 2015).

Em 2014, as exportações de vinho do Rio Grande do Sul somaram, aproximadamente, mais de nove milhões de dólares, correspondendo a $87,23 \%$ das exportações nacionais de vinhos. De acordo com o Instituto Brasileiro do Vinho (Ibravin, 2015), o Brasil consolidou-se como o quinto maior produtor de vinhos do Hemisfério Sul e é um dos mercados que vêm crescendo mais rapidamente, o que evidencia o grande potencial da vitivinicultura brasileira.

Nesse cenário, no Brasil, tecnologias modernas na produção do vinho têm permitido obter uma bebida de boa qualidade, superando-se limitações do terroir, ou qualidades específicas locacionais, de terra e clima, que possibilitam um vinho superior (Sato, 2006). Tal fato condiciona-se aos avanços enológicos e tecnológicos de produção, processamento e armazenamento do produto. Observa-se que, atualmente, várias vinícolas têm incorporado o uso de máquinas sofisticadas, desde novos tipos de filtros, de engarrafadeiras, de tanques, entre outras.

Contudo, a indústria vitivinícola nacional tem enfrentado intensos desafios em função da abertura de mercado. Dentre tantos, destacam-se a entrada da concorrência internacional, com introdução dos vinhos 
importados, e as mudanças acentuadas na preferência dos consumidores (Thomé et al., 2013, citados por Debastiani, Leite \& Boelhouwer, 2015). Essa realidade reflete bem as afirmações de Porter (1999) quanto à importância de implantação de estratégia de diferenciação, em que a empresa busca ser única no mercado, mesmo com o apelo de organizações estrangeiras.

Nesse aspecto, em seu estudo, Sato (2006) afirma que, para atingir altos padrões de qualidade, as vinícolas brasileiras estão em desvantagem competitiva frente aos países produtores que apresentam vantagens na especificidade de localização, como Argentina e Chile, por estarem em zonas de aptidão de clima e solo. Aqui, enquadra-se a possibilidade e/ou viabilidade de empregar a estratégia de manutenção, pois considera-se um caso em que a empresa está enfrentando ou espera encontrar dificuldades e, diante dessa situação, toma-se uma atitude defensiva frente às ameaças.

Somada a isso, por ser um mercado caracterizado por volatilidade, a exigência de organizações inovadoras e dinâmicas tem sido fundamental para possibilitar a perpetuidade neste ramo. As estratégias de cooperação e coopetição complementam o paradigma competitivo, em que surgem novas formas de governança intraorganizacional. Nesta, os agentes têm uma mútua interação, agregando valor em determinadas atividades e, simultaneamente, competindo pelos mesmos recursos em outras, procurando maximizar seus lucros (Monticelli et al., 2013, citados por Debastiani et al., 2015).

Os custos para atingir a qualidade equivalente, provavelmente são mais elevados no Brasil, exigindo-se das vinícolas brasileiras um gerenciamento estratégico mais elaborado, investimento em tecnologia e parcerias (Sato, 2006). Nesse caso, posicionar-se estrategicamente com o intuito de obter liderança pelo custo total pode ser fundamental, pois, ao adotar-se uma posição de custos mais baixos do que os da concorrência, mantendo, porém, a qualidade, a empresa consegue ter maior retorno financeiro e também ampliar sua participação no mercado.

Nesse contexto, no tocante ao mercado do vinho, novas regiões têm surgido, produzindo vinhos de excelente qualidade, apesar da ideia de que 
bons vinhos só podiam ser produzidos em regiões tradicionais com sólida reputação, como, por exemplo, França e Itália. Atualmente, porém, com o uso da tecnologia, novas regiões produtoras (África do Sul, Austrália, Chile, Estados Unidos, Nova Zelândia) vêm se destacando (Souza, Macêdo \& Mello, 2011).

Assim, aliado ao surgimento dos vinhos das novas regiões produtoras, tem-se o Vale do São Francisco, que produz vinhos mais leves e frutados que conquistam cada vez mais o consumidor em escala mundial (Editora Abril, 2006, citado por Souza et al., 2011).

\subsection{A VINICULTURA NO VALE DO SÃO FRANCISCO}

No Nordeste do Brasil, a vitivinicultura é uma atividade que vem sendo intensificada nos últimos anos. É importante verificar a disponibilidade de terras, mão de obra especializada, tecnologia, capital, mercado, logística, créditos, subsídios, experiência das empresas no ramo, entre outros componentes, para compreender o surgimento e o crescimento dessa atividade nessa região (Vital, Moraes \& Ferraz, 2005).

O Vale do São Francisco, aí localizado, abrange grande parte dos estados de Pernambuco e da Bahia. Suas vinícolas produzem diversos tipos de vinhos finos tintos, brancos e espumantes, chamados de "vinhos tropicais" devido às características do clima tropical semiárido e suas particularidades que o tornam um diferencial para o setor. Trata-se da segunda maior região produtora de vinhos do Brasil, com uma área cultivada de aproximadamente 500 ha de vinhedos e uma produção anual de seis milhões de litros de vinhos finos (Biasoto, Pereira, Oliveira \& Menezes, 2014).

O clima semiárido sempre considerado um entrave ao crescimento da região, segundo Nóbrega (2004), tornou-se uma vantagem competitiva, constituindo uma excelente característica para a agricultura que tem como base a tecnologia da irrigação. Entre as vantagens estão: a baixa umidade relativa do ar e a pluviosidade, a grande luminosidade e a constância de calor que se apresentam durante todo o ano. 
O clima quente e seco resultante é ideal para plantar e colher em qualquer época do ano atingindo uma produtividade superior à média nacional. Outra observação é que a insolação diminui as perdas com pragas e distúrbios fitossanitários. Além disso, outro aspecto que favorece a região diz respeito à sua localização estratégica. Ela situa-se próxima a importantes capitais do Nordeste (cerca de $770 \mathrm{~km}$ do Recife; $520 \mathrm{~km}$ de Salvador e $850 \mathrm{~km}$ de Fortaleza) e mais próxima do mercado europeu e americano do que os portos da região sudeste do país (Silva et al., 2000), o que contribui para as exportações.

O Vale tem, portanto, característica peculiar, pois é a única região vinícola do mundo situada no clima semiárido e desponta como uma nova fronteira internacional na produção de vinhos finos.

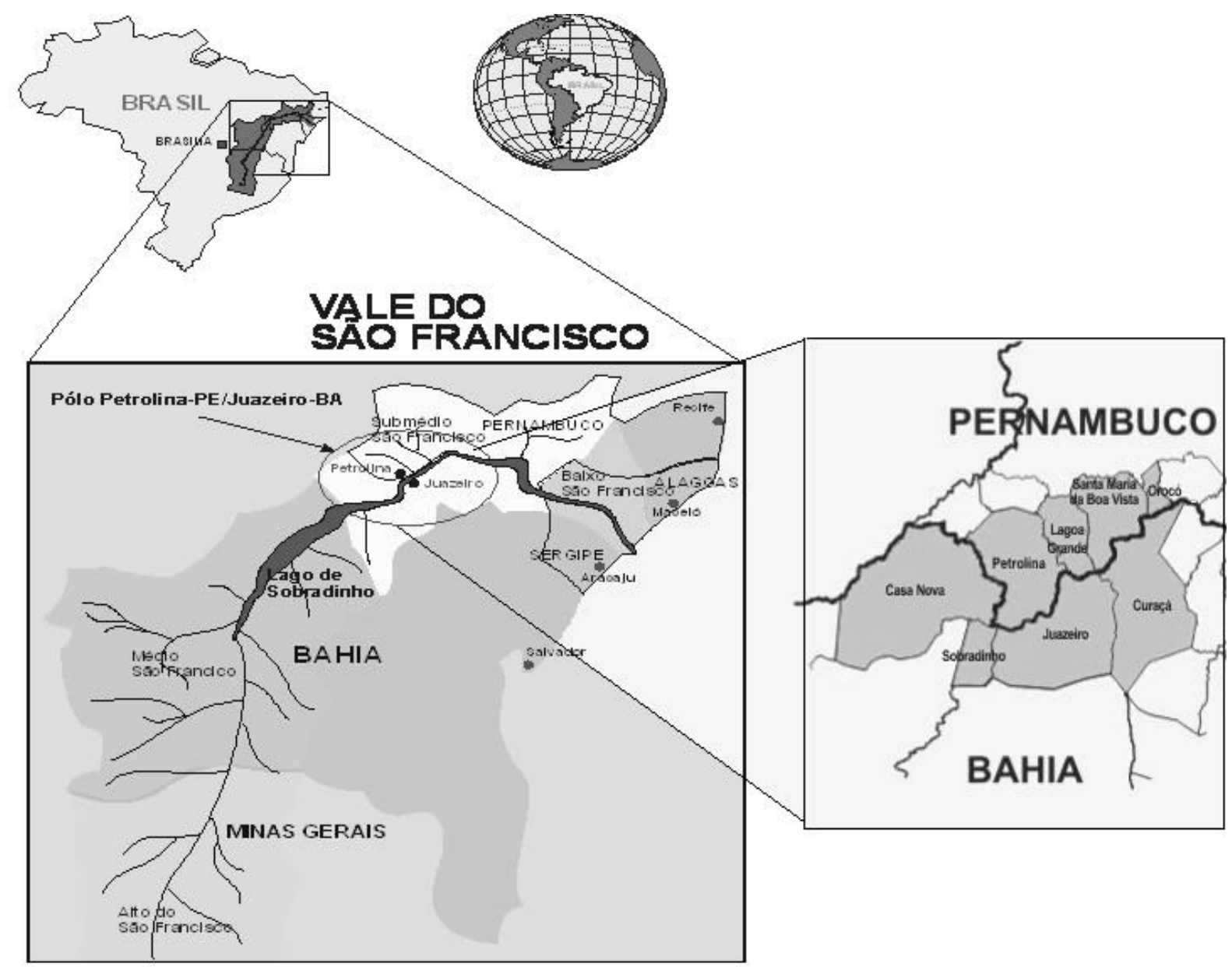

Figura 1: Localização do polo fruticultor Vale do São Francisco

Fonte: adaptado de Silva (2001) 
Os atrativos da área são bastante razoáveis: solo, temperatura e regime de chuvas favoráveis, além da infraestrutura de irrigação ali montada pela Companhia de Desenvolvimento do Vale do São Francisco (Codevasf) e da elevada insolação anual (3.000 horas por ano). Com isso podem ser obtidas cinco safras de uva a cada dois anos, o que reduz muito o custo de produção e permite a obtenção de uvas de boa qualidade.

Em Pernambuco, as vinícolas localizam-se nos municípios de Petrolina, Lagoa Grande e Santa Maria da Boa Vista, há também outra localizada no município de Casa Nova, na Bahia. Nessa localidade, aproximadamente 12 vinícolas produzem vinhos finos. Segundo Teruchkin (2004, citado por Souza, 2009), a produção de vinho fino está ligada diretamente à qualidade, ou seja, à produção de um produto de maior valor agregado.

Em sua pesquisa, Souza (2009) observa que o setor de vitivinicultura do Vale é definido como um arranjo produtivo local, o que pressupõe que haja vínculos e interações entre seus integrantes. Nesse sentido, existem as associações como a Valexport, onde funciona o Grupo do Vinho do Vale, e o Vinhovasf. Também o estado de Pernambuco, juntamente com a Embrapa Uva e Vinho, Embrapa Semiárido e Valexport, possui projeto de pesquisa e cooperação técnica com o objetivo de qualificar a vitivinicultura no Submédio São Francisco e possibilitar o desenvolvimento de vinhos típicos da região.

Por outro lado, o autor ainda considera que, apesar de reconhecerse que o desenvolvimento (ou mais que isso, a sobrevivência) do setor está intrinsecamente ligado ao investimento em pesquisas tecnológicas que apontem as melhores técnicas de manejo no campo e vinificação em condições tão inovadoras (i.e. em baixas latitudes, em regiões que não possuem tradição em vitivinicultura), percebe-se que diferenças nas características das empresas, refletidas, por exemplo, em maior ou menor autonomia para investimentos e pesquisas têm afastado as empresas das ações conjuntas. Assim, relações assimétricas entre as vinícolas podem comprometer a cooperação e o alcance de melhores resultados para o arranjo (Souza, 2009). 
Logo, pelo fato de a produção de vinhos estar em alta nas vinícolas do Vale do São Francisco, como afirma estudo do G1, a região já é responsável por produzir oito milhões de litros da bebida por ano. Esses vinhos abastecem cerca de $15 \%$ do mercado interno nacional e movimentam entre $R \$ 600$ milhões e $R \$ 1$ bilhão de reais por ano ( $G 1$, 2017).

Atrelada a esse fator, a irrigação exerce papel fundamental. Graças a ela, tem sido possível produzir vinhas e elaborar vinhos varietais na região tropical e semiárida do Vale do São Francisco, no Nordeste. Como se não bastasse essa inovação, nessa área a produtividade dos plantios de vinhas está bem acima das obtidas nas regiões temperadas (Lima, 2006). Devido a esses aspectos, trata-se de um caso peculiar e único no mundo.

Com relação à gestão de negócios, verifica-se que as vinícolas adotam estratégias variadas. Do ponto de vista do mercado de atuação, há as que privilegiam o mercado regional, outras o mercado nacional, e outras o nacional e o internacional (Souza, 2009). No tocante à entrada no mercado internacional, observa-se que esta é uma alternativa estratégica para a obtenção de novos consumidores e de maior reconhecimento no mercado nacional. No caso específico do setor vinícola, a concorrência com vinhos importados tem levado as empresas nacionais do ramo a buscarem mercados além das fronteiras nacionais (Zen et al., 2013).

Estudos mostram que um gargalo a ser superado, mencionado por produtores entrevistados em pesquisa aplicada (Lima, 2006), é a comercialização, ainda deficiente e carente de uma maior dinamização pela ampliação do mercado e de campanhas de marketing para que os produtores possam melhorar sua posição de barganha com os distribuidores e supermercados. Apesar disso, o autor considera que as potencialidades para a expansão da produção de vinho no Vale do São Francisco são bastante promissoras, o que tem permitido uma rápida expansão da produção e da área cultivada (Lima, 2006).

No entanto, como uma inovação, esses produtos enfrentam o desafio de convencer o mercado a aceitá-los e a reconhecer a sua qualidade, o que envolve, além da questão da produção, também a da sua representação cultural na sociedade. Isso indica como esses vinhos são 
percebidos e as imagens atreladas a eles (Souza et al., 2011). Assim, associada às estratégias tecnológicas na vitivinicultura está a carência do aperfeiçoamento de uma imagem frente ao consumidor. Kotler (2009) afirma que a imagem é a maneira como o público percebe a empresa ou seus produtos. Logo, reforça-se a necessidade de essas empresas e seus produtos desenvolverem sua imagem no mercado.

Para Hooley (2011, p. 25), "o estabelecimento de uma estratégia eficaz de marketing começa com uma análise detalhada e criativa tanto das capacidades da empresa quanto das oportunidades e ameaças apresentadas pelo ambiente". Em suma, nota-se que as novas estratégias devem tratar o cliente como parte integrante de todo o processo.

Ainda de acordo com Lima (2006), mesmo com um número reduzido de produtores de porte médio, o volume de produção da região é expressivo e crescente, o que já proporciona às empresas vinícolas algumas das vantagens de aglomeração em termos de presença de fornecedores, capacitação de mão de obra, divulgação dos vinhos locais e de facilidades de comercialização, troca de informações e acesso aos órgãos de apoio tecnológico, etc. (Lima, 2006).

Sato (2006) observa em seu trabalho que a especificidade locacional, ou seja, as condições de clima e solo especiais para exploração de vinhos finos são um fator muito forte na definição estratégica da empresa, e têm levado as empresas a se expandirem para locais como a região do Vale do São Francisco, no Nordeste brasileiro. Outras estratégias utilizadas são as parcerias com vinícolas locais que já apresentam aptidão de explorar vinhedos, mas não possuem o conhecimento tecnológico de varietais europeias para produção de vinhos finos.

Por outro lado, Crisóstomo e Sicsú (2009) abordam que a vinicultura na região do Submédio do Vale do São Francisco está organizada segundo as estratégias de cooperação e de cooperação competitiva. Quanto à estratégia de cooperação, são notórios os acertos entre os stakeholders ao longo da cadeia produtiva - a jusante e a montante -, nos quais é possível ressaltar os apoios governamentais e os elos com órgãos de pesquisa sediados na região. 
Vital (2009) considera em seu trabalho que o mercado é diferenciado para aqueles que têm marca já conhecida pelos consumidores. Além da marca, é preciso que o produto esteja dentro das grandes redes de distribuição, tenha qualidade e preço competitivos. Nesse particular, as empresas instaladas no São Francisco diferem em relação à inserção no mercado.

As maiores têm marca conhecida e canais de escoamento do produto garantido tanto no país como no exterior. As empresas menores diferem entre as que conseguiram firmar a marca e entrar nas grandes redes de distribuição e as que ainda estão buscando esse espaço de negócio (Vital, 2009). Esse comportamento, de acordo com Churchill (2000), se dá devido aos clientes valorizarem itens em que imagem e marca são vinculadas à mídia. Em outras palavras, quando produtos e/ou marcas possuem imagens bem definidas e/ou claras, isso ajuda os potenciais compradores a entenderem o valor que está sendo oferecido. Neves e Castro (2011) completam ao afirmar que o sucesso nas estratégias adotadas para esses e outros objetivos depende de novas ações e ideias que as empresas devem desenvolver continuamente, em formato de iniciativas e vantagens.

Por fim, Sato (2006) reforça que o posicionamento do produto no mercado depende também de oferecer um produto de qualidade com preço competitivo. Adicionalmente as vinícolas estão estruturando hierarquias de qualidade via processos de certificação que irão segmentar o mercado por qualidade/preço e garantir rastreabilidade de origem e compromisso da qualidade atestada.

\section{CONCLUSÕES}

O Vale do São Francisco destaca-se como um grande polo produtor de frutas, voltado tanto à exportação quanto ao mercado interno, mas a produção de vinhos tem também importância não apenas no aspecto econômico, mas também turístico. Devido ao clima quente e seco da região, as videiras produzem até três vezes por ano, sendo este o único lugar do planeta onde isso acontece. 
Diante do exposto, após as análises e discussões sobre a atuação do setor vinícola no mercado nacional, percebe-se que as estratégias utilizadas pelas organizações são diversas e, em alguns casos, dependendo de alguns fatores, ineficientes, o que as limita e as torna menos competitivas frente a outras vinícolas, principalmente as estrangeiras.

Logo, considerando que o tema principal abordado nesta pesquisa enquadra-se no âmbito de futuros estudos, análise de tendências e estratégias de organizações, o presente artigo atingiu seu objetivo de estudar, a partir da revisão da literatura, as estratégias de inserção no mercado brasileiro e as barreiras enfrentadas pelas vinícolas do Vale do São Francisco pernambucano. Em acordo com o objetivo proposto neste trabalho, a análise dos resultados possibilitou também conhecer o perfil das empresas do setor vinícola e suas posições diante das diversas ameaças e oportunidades ofertadas pelo mercado nacional.

Assim, com a realização do estudo, foi possível ter um conjunto de informações relevantes para analisar as formas de comercialização dos vinhos no mercado nacional, além de poderem ser detectados mais facilmente conflitos e problemas de coordenação nessa cadeia produtiva. Nesse sentido, o artigo pode também pretendeu trazer como contribuição análises sobre as melhores formas de inserção das empresas nas redes de comercialização.

Na indústria do vinho, o marketing, por exemplo, pode ser muito útil na promoção de estratégias abrangentes, coesivas e eficazes para as empresas efetivamente competirem no mercado atual. Em suma, no mercado do vinho, o mix promocional é um componente importante e, se bem tratado, pode garantir o sucesso no mercado ou pode encurtar o ciclo de vida do produto.

Ao estudar as barreiras, as estratégias e as relações com os canais de distribuição, pode-se contribuir de forma relevante para a melhoria da competitividade. Uma vinicultura mais competitiva depende tanto de boas técnicas de cultivo da matéria-prima e de fabricação quanto de uma gestão eficiente do marketing e da comercialização. Melhorando-se esses aspectos, melhora-se também o padrão competitivo das vinícolas. 


\section{REFERÊNCIAS}

Azevedo, P. F. (2007). Comercialização de produtos agroindustriais. In M. O. Batalha (Coord.), Gestão agroindustrial (3a ed.). São Paulo: Atlas. p. 63-112.

Bain, J. (1956). Barriers to new competition. Cambridge, Mass.: Harvard University Press.

Balbim Junior, A. B., \& Bornia, A. C. (2011). Proposta de instrumento de medida para avaliar a satisfação de clientes de bancos utilizando a Teoria da Resposta ao Item. Gestão e Produção, 18(3), 541-554.

Barney, J. (2001). Resource-based theories of competitive advantage: a ten years retrospective on the resource based view. Journal of Management, 27(1), 643-650.

Bateman, T. S., \& Snell, S. (1998). Administração: construindo vantagem competitiva. São Paulo: Atlas.

Bhalla, A., Lampel, J., Henderson, S., \& Watkins, D. (2009). Exploring alternative strategic management paradigms in high-growth ethnic and non-ethnic family firms. Small Business Economics, 32(1), 77-94.

Biasoto, A. C. T., Pereira, G. E., Oliveira, J. B., Menezes, T.., \& Leão, P. C. S. (2014). Efeitos da desfolha e desponte de ramos sobre a composição físico-química de Syrah elaborados em dois ciclos de produção no Vale do São Francisco. Anais do Congresso Brasileiro de Fruticultura, 23, Cuiabá, MT, Brasil.

Bucheroni, F. (2015). Planejamento estratégico: curso Online Endeavor. Recuperado em 18 de maio, 2017, de http://cursos.endeavor.org.br/

Campos, V. F. (2004). TQC: controle da qualidade total: no estilo japonês (8a ed.). Nova Lima: INDG Tecnologia e Serviços. 256 p.

Carlton, D. (2004). Why barriers to entry are barriers to understanding. American Economic Review, Papers and Proceedings of the Annual Meeting of the American Economic Association 94, 116.

Carlton, D., \& Perloff, J. (1994). Modern industrial organization. New York: HarperCollins College.

Chiavenato, I. (2007). Administração: teoria, processo e prática. Rio de Janeiro: Elsevier.

Churchill, G. A. (2000). Marketing: criando valor para os clientes. São Paulo: Saraiva.

Corrêa, R. M, Murini, L. T, Becker, D. V., \& Boligon, J. A. R. (2012). Análise do composto de marketing segundo a visão dos consumidores na Ferragem Rio Branco. Disciplinarum Scientia, 8(1), 1-17. 
Crisóstomo, A. P., \& Sicsú, A. B. (2009). Inovação tecnológica competitiva no Semiárido do Vale do São Francisco: um estudo das empresas vinícolas. Anais do Congresso de Desenvolvimento Regional de Cabo Verde.

Debastiani, G., Leite, A. C., Weiber Junior, C. A., \& Boelhouwer, D. I. (2015, julho/dezembro). Cultura da uva, produção e comercialização de vinhos no Brasil: origem, realidades e desafios. Revista Cesumar Ciências Humanas e Sociais Aplicadas, 20(2), 471-485ez.

Dias, S. R. (2003). Gestão de marketing. São Paulo: Saraiva.

Fernandes, I. et al. (2013). Planejamento estratégico: análise SWOT. Revista Conexão Eletrônica, 1464-1473.

Ferrell, O. C., \& Hartline, M. D. (2005). Estratégia de marketing. 3. ed. São Paulo: Pioneira Thomson Learning.

Fink, A. (2005). Conducting research literature reviews: from internet to paper (2nd ed.). Thousand Oaks: Sage.

G1 - Portal de notícias. (2017). Produção de vinhos está em alta nas vinícolas do Vale do São Francisco. Recuperado em 27 de maio, 2017, de http://g1.globo.com/pe/petrolina- regiao/noticia/2017/03/producao-devinhos-esta-em-alta-nas-vinicolas-do-vale-do-sao- francisco.html

Gouvêa, M. A., \& Niño, F. M. (2010, janeiro/abril). A diferenciação no processo de posicionamento de marketing e o setor de turismo. Gestão \& Regionalidade, 26(76).

Guetta, A. et al. (2013). Franchising: aprenda com os especialistas. Rio de Janeiro: ABF-Rio.

Hooley, G. J., Saunders, J. A., \& Piercy, N. F. (2005). Estratégia de marketing e posicionamento competitivo. São Paulo: Pearson Prentice Hall.

Hooley, G. (2011). Estratégia de marketing e posicionamento competitivo (4a ed.). São Paulo: Pearson Prentice Hall.

Instituto Brasileiro do Vinho- Ibravin. (2015). Regiões produtoras. Recuperado em 21 de maio, 2017, de http://www.ibravin.org.br/regioesprodutoras.php

Kotler, P. (1998). Administração de marketing: análise, planejamento, implementação e controle (5. ed.). São Paulo: Atlas.

Kotler, P. (2000). Administração de marketing: a edição do novo milênio. São Paulo: Pearson Prentice Hall.

Kotler, P. (2009). Administração de marketing: análise, planejamento, implementação e controle (5a ed.). São Paulo: Atlas. 
Kotler, P., \& Armstrong, G. (2003). Princípios de marketing (9a ed.). São Paulo: Prentice Hall.

Kotler, P., \& Keller, K. L. (2006). Administração de marketing. São Paulo: Pearson Education do Brasil.

Kotler, P., \& Keller, K. L. (2012). Administração de marketing (14a ed.). São Paulo: Pearson Education do Brasil.

Lima, J. P. R. (2006, julho/setembro). Cachaça artesanal e vinhos finos no Nordeste: desafios, potencialidades e indicações de políticas. Revista Econômica do Nordeste, 37(4).

Lins, H. S., Silva, M. M. N., Abreu, H. J. L. F. M., \& Costa, A. C. S. (2010). Estratégias de marketing utilizadas por comerciantes informais: o caso do churrasquinho. Anais do Encontro Nacional de Engenharia de Produção, 30, São Carlos, SP, Brasil.

Luz, G. I. (2014). Posicionamento e construção de imagem através do facebook: estudo de caso da fanpage da prefeitura municipal de Curitiba. Trabalho de conclusão de curso, Universidade Federal do Rio Grande do Sul, Porto Alegre, RS, Brasil.

McCarthy, E. J. (1978). Basic marketing: a manageriaI approach (6th ed.). Homewood: Richard D. Irwin.

Melo, J. R., Forte, S. H. A. C., \& Sousa Filho, J. M. A. (2014). Indústria bancária brasileira: um estudo sobre as barreiras de entrada às instituições estrangeiras. Revista Ibero-Americana de Estratégia, 13(3), p. 63-76.

Mintzberg, H., Ahlstrand, B., \& Lampel, J. (1998). Strategy safari: a guided tour through the wilds of strategic management. New York: Free Press.

Mintzberg, H, Ahlstrand, B., \& Lampel, J. (2000). Safári de estratégia: um roteiro pela selva do planejamento estratégico. Porto Alegre. Bookman.

Neves, M. F., \& Castro, L. T. (2011). Marketing e estratégia em agronegócios e alimentos. São Paulo: Atlas.

Nóbrega, I. N. S. F. (2004). Crescimento e desenvolvimento da fruticultura irrigada no Vale do São Francisco. Monografia, Universidade Católica de Pernambuco, Recife, PE, Brasil.

Oliveira, L. M., Perez JR., J. H., \& Silva, C. A. S. (2005). Controladoria estratégica (3a ed.). São Paulo: Atlas.

Popovic, D. (2006). Modelling the marketing of high-tech start-ups. Journal of Targeting, Measurement and Analysis for Marketing, 14(3), 260-276.

Porter, M. E. (1999). Competição: estratégias competitivas essenciais (14a ed.). Rio de Janeiro: Campus. 
Porter, M. E. (2004). Estratégia competitiva: técnicas para análise de indústrias e da concorrência (2a ed.). Rio de Janeiro: Campus.

Rosa, S. E. S, \& Simões, P. M. (2004, março). Desafios da vitivinicultura brasileira. BNDES Setorial, 19, 67-90.

Sato, G. S. (2006, julho/dezembro). Vinhos brasileiros: é possível a internacionalização? Revista Eletrônica de Negócios Internacionais da ESPM, 1(1), 243-259.

Schultz, D. E. (2001). Marketers: bid farewell to strategy based on old 4Ps. Marketing News, 35(2), 7.

Silva, J. M. A., Rezende, A. M., \& Silva, C. A. B. (2000, janeiro/março). Condicionantes do desenvolvimento do pólo agroindustrial de Petrolina/Juazeiro. Revista Econômica do Nordeste, 31(1), 48-64.

Silva, D. O. da, Bagno, R. B., \& Salerno, M. S. (2014). Modelos para a gestão da inovação: revisão e análise da literatura. Production, 24(2), 477-490. Recuperado em 1 de maio, 2017, de http://www.scielo.br/pdf/prod/2013nahead/aop_0750-12.pdf

Silva, P. C. G da. (2001). Articulação dos interesses públicos e privados no polo Petrolina-PE/Juazeiro-BA. Tese de Doutorado), Universidade Estadual de Campinas, SP, Brasil.

Souza, A. C. R. (2009). O "Circuito da Cultura" e a estruturação de um discurso: fazendo sentido do vinho do Vale do São Francisco. Tese de Doutorado, Universidade Federal de Pernambuco: Recife, PE, Brasil.

Souza, A. C. R, Macêdo, J. S, \& Mello, S. C. B. (2011, julho/setembro). A representação do vinho do Vale do São Francisco na mídia. Revista de Administração e Inovação, 8(3), 6-32.

Thomé, R. B. M., Hexsel, A. E, Toni, D., \& Milan, G. S. (2013). Estrutura e posicionamento estratégico da indústria de vinhos de mesa do Rio Grande do Sul. Revista Brasileira de Estratégia - Rebrae, 6(2), 151-164.

Toledo, M. L., \& Ferreira, K. A. (2016). Adoção da estratégia de postponement em uma empresa vitivinícola de Minas Gerais. Anais do Encontro Nacional de Engenharia de Produção, 36, João Pessoa, PB, Brasil.

Vital, T. (2009, julho/setembro). Vitivinicultura no Nordeste do Brasil: situação recente e perspectivas. Documentos Técnico-científicos: Revista Econômica do Nordeste, 40(3).

Vital, T. W., Moraes, F. R., \& Ferraz, F. Z. E. (2005). Vitivinicultura no Nordeste do Brasil: um arranjo produtivo em expansão. Anais do Congresso da Sober, 43, Ribeirão Preto, SP, Brasil. 
Vitorino Filho, V. A., Peresin, G. L., \& Sacomano Neto, M. (2011). Vantagem competitiva: uma releitura teórica de Porter. Área Temática: Estratégia Empresarial. Anais do Congresso Virtual Brasileiro de Administração, 8.

Zikmund, W. G. (2003). Business research methods (7th ed.) Ohio: Thomson South Western.

Zen, A. C., Dalmoro, M., Fensterseifer, J. E., \& Wegner, D. (2013). Desenvolvimento de recursos em redes interorganizacionais e o processo de internacionalização: o caso Wines of Brasil. Revista Ibero-Americana de Estratégia, 12(1), 107-130. 